\title{
Development of Biopesticide Bauveria bassiana Bals. (Vuill.) Fungi For Pest Control Vegetable in Berastagi
}

\author{
Sularno \\ Lecturer of Faculty of Teacher Training and Education UISU \\ svlarno@yahoo.com
}

\begin{abstract}
This research was conducted in two stages. The research method is the isolation and application of biopesticide. In the first stage aims to isolate entomopathogenic fungi Beauveria bassiana around Berastagi vegetable farms and grow on agar and corn mashed artificial medium. Testing the virulence of Beauveria bassiana in vitro in several types of vegetable pests before it is applied on agricultural land. In phase II aims to application B. bassiana in the vegetable patch. In the in vitro treatment, the ability to infect insects beauvria average reached 75\%., Controls on crop lands, in the third week began their Crocidolomia pests that attack the growing point so that the cabbage plants fail to bloom. Average cropland applied biopesticides B. bassiana has been no attack. At week 7 attacks on control plants reach 13 plants or 17.3\%. In field applied while Beauveria bassiana attack reached six plants, or about $8 \%$.
\end{abstract}

Keyword: Bioinsectisida, Beauveria bassiana Bals. (Vuill.), Chemical pesticides, vegetables

\section{INTRODUCTION}

Pesticides can cause acute and long-term effects for farm workers who are exposed. Exposure to pesticides can cause varying effects ranging from irritation to the skin and eyes to a more deadly effect that affects the nerve, disrupting the reproductive hormone system and cause cancer. In 2007,a study in non-Hodgkin's lymphoma and leukemia showed a positive association with exposure to pesticides. Strong evidence also shows that the negative effects of pesticide exposure include neurological damage, congenital abnormalities, fetal death and developmental disorders of the nervous system. The American Medical Association recommends limiting exposure to pesticides and starts using safer alternatives (Jakubowski,. 2011). The use of pesticides increases the number of issues on the environment. More than $90 \%$ insecticides and $95 \%$ herbicides are sprayed toward the place that was not targeted. Flow pesticides occur when pesticides suspended in the air as particles carried by the wind to other areas, potentially causing pollution. Pesticides are the main problems of water pollution, and some pesticides are persistent organic pollutants that cause ground contamination. Pesticides also reduce agricultural biodiversity in the soil, thereby reducing the rate of nitrogen fixation. loss of pollinators, destroy habitat (especially bird habitats), and harm endangered animals. Over time, the pest species can develop resistance to pesticides so it takes research to develop new pesticides. Of the approximately one million species of insects are known, approximately 15,000 species known as pests. Along with the increase in agricultural activity, interference also increases insect pests that cause damage or destruction of food crops (Bale, et al, 2008). Fortunately, most insect pests have the potential pathogenic microorganisms associated with it. One of these microorganisms is an entomopathogenic fungus. Entomopathogenic fungi are microorganisms that are used first as a biological pest 
Sularno, Edi Azwar : Development of Biopesticide Bauveria bassiana Bals. (Vuill) Fungi For Pest Control Vegetable in Berastagi.

control agent. More than 700 species from 90 genera of fungi are pathogenic to insects (Khan, et al, 2012). Most species of entomopathogenic fungi derived from the division Ascomycota and Zygomycota. Generally fungal pathogens of insects include Metarhizium anisopliae, Beauveria bassiana, Nomuraea rileyi, Paecilomyces farinosus and Paecilomyces fumosoroseus (Takhur and Sandhu, 2010), Lagenidium, Coelomomyces, Conidiobolus, Entomophaga, Entomophthora, Erynia, Neozygites, Pandora, Zoophthora, Cordyceps, Hypocrella, Torrubiella, Aschersonia, Hirsutella, Tolypocladium and Verticillium (Pell and Shah, 2003).

\section{Lifecycle Fungi entomopathogenic}

The life cycle starts from the entomopathogenic fungi spores germinate to form a mycelium, the mycelium is then reshaped spores. Entomopathogenic fungi life cycles generally consist of two phases. The first phase is normal mycelial growth that occurs outside the host body and budding yeast-like phase occurs within the host homeosol.

\section{Enzymes of virulent entomopathogenic Fungi}

Initial interaction in the pathogenicity is mediated by a mechanical force, enzymatic process and the strength of certain acids. These enzymes responsible for the interactions of fungi with their hosts and environment. The enzymes involved in the pathogenicity of a group of insects generally protease, peptidase, chitinase, and lipase. Its main constituent insect cuticle chitin and protein degradation by protease and a peptidase enzyme. Another role as a growth factor saprophytic fungi, propanol oxidase activation in the hemolymph and as a virulence factor of fungi (Khan, et al, 2012). The main component of insect cuticle is the chitin substance. Therefore both endo and Ekto khitinase plays an important role in breaking down the N-acetylglucosamine (NAGA) the polymer of insect cuticle becomes smaller monomer units. So that the enzyme chitinolytic also be a virulence determinant factor of fungi. While the lipase enzyme plays a role in epicuticular parse the outer surface of insects composed of a mixture of non-polar lipid complex (Blomquist and Vogt, 2003).

\section{Host range entomopathogenic Fungi}

Entomopathogenic fungi have a very broad host range in the class Insecta. Insect pests are hosts from Lepidoptera, coleopteran, Diptera, Orthoptera and other insect orders. Entomopathogenic fungi, Verticillium lecanii, Beauveria bassiana and Metarhizium anisopliae intensively studied for use as the main natural enemies of the pest aphid and other major agricultural pest (Roberts and St. Leger, 2004). Beauveria bassiana (Bals.) Vuill. Has been developed as a microbial insecticide to eradicate many major pests, including lepidopterans and orthopterans. approximately $33.9 \%$ of mycoinsecticide made of B. bassiana, Metarhizium anisopliae followed by (33.9\%), Isaria fumosorosea (5.8\%) and Beauveria brongniartii (4.1\%) (Wraight and Carruthers, 1999). Therefore, the presence of fungi, these fungi play a major role in overcoming the vegetable pests in vegetable organic Brastagih as centers in North Sumatra.

\section{Materials and Methods}

Step 1. Exploration research includes fungi present on the ground around the roots of plants with a depth of 5 to $15 \mathrm{~cm}$. Soil samples were collected in accordance with the determination of sampling. Soil is then inserted into the plastic and mixed until homogenous. 2. Soil samples were obtained is put into a plastic container, filled with about half of the volume of the container. 3. Before larvae Tenebrio molitor inserted, the soil in the container moistened with enough water added. 4. Putting worm Tenebrio molitor at 
Sularno, Edi Azwar : Development of Biopesticide Bauveria bassiana Bals. (Vuill) Fungi For Pest Control Vegetable in Berastagi.

ground level in the container, which included caterpillar is a caterpillar newly molted (molting) is white 5. Further containers are closed using gauze that caterpillars are not out of the container, then incubated for 1 to 2 weeks in a dark place in order to trap caterpillars move on, so it's easy contact with entomopathogenic fungi that are in the soil samples.

\section{Isolation stage}

The isolate phase includes 1. Tenebrio molitor caterpillars that infected Beauveria bassiana fungi were isolated by instilling sample of infected tissue on the medium Potato dextrose Agar (PDA) and incubated for 5 to 7 days 2. Insulation is done by dipping the infected tissue samples (worm Tenebrio molitor) while ( \pm 3 minutes) to a solution of clorox, alcohol, and then rinsed with sterile distilled water. 3.fungi growing on media is identified and transmitted back (reinokulate) on the test insects. Virulence test is done by calculating lethal concentration 50\% (LC50) and 50\% lethal dose (LD50). 4. virulent entomopathogenic fungi reproduced and developed to control the fi

\section{Isolation of Beauveria bassiana}

Stages isolation covers 1. Tenebrio molitor larvae infected with Beauveria bassiana Fungi were isolated by instilling sample of infected tissue on the medium Potato dextrose Agar (PDA) and incubated for 5 to 7 days 2. Insulation is done by dipping the infected tissue samples ( Tenebrio molitor) while ( \pm 3 minutes) to a solution of clorox, alcohol, and then rinsed with sterile distilled water. 3.fungi growing on media is identified and transmitted back (reinoculate) on the test insects Sometimes the isolation process had to be repeated because of contamination by other bacteria or fungi. Kesabarabn and accuracy needed to obtain pure isolates before propagated in the propagation medium (corn).

Here is a picture Tenebrio molitor larvae infected with Beauveria bassiana

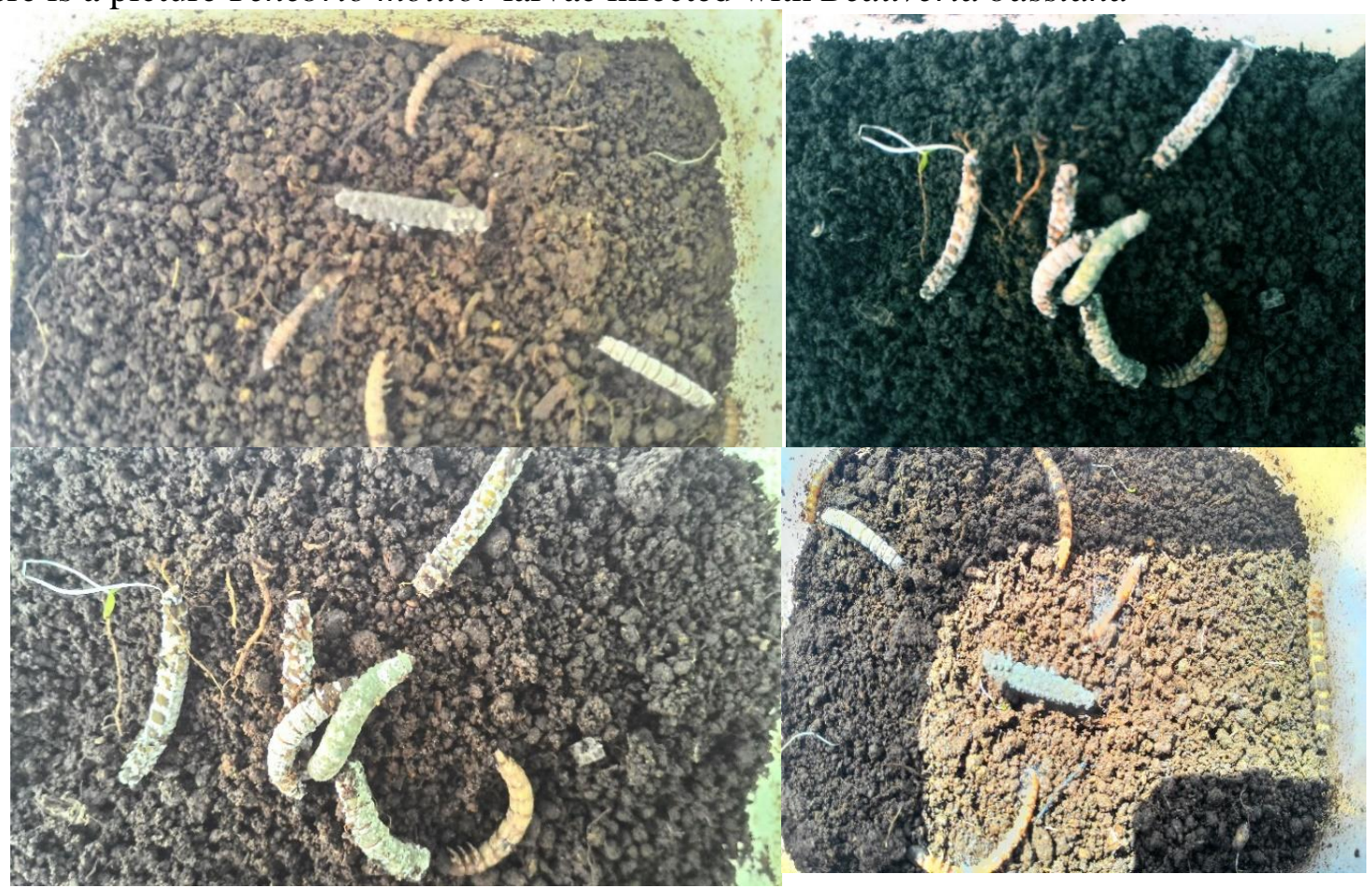

Figure . Tenebrio molitor larvae infected with Beauveria bassiana and Metarhizium Anisopliae

Stage Purification And the multiplication of Beauveria bassiana 
Sularno, Edi Azwar : Development of Biopesticide Bauveria bassiana Bals. (Vuill) Fungi For Pest Control Vegetable in Berastagi.

Beauveria bassiana purification method is done by streak plate method or by pour plate method on PDA media. Beauveria bassiana already growing on the PDA medium and then reproduced in corn medium. Mashed corn steamed later washed Clean Up nearly ripe. Enter Into plastic glass hearts and sterilized using an autoclave. Corn medium cold ready for review inoculated with Beauveria bassiana as a propagation medium. Beauveria bassiana is well propagated used to review applications Pest control Plants flower cabbage Brassica oleracea.

From in vitro experiments on the data obtained as follows:

Table. Number of Tenebrio molitor larvae infected and died after treatment with Beauveria bassiana

\begin{tabular}{|c|c|c|c|c|}
\hline \multirow{2}{*}{$\begin{array}{l}\text { Repeat of Treatment with } 10 \\
\text { T.molitor larvae }\end{array}$} & \multicolumn{5}{|l|}{ Number larvae T.molitor infected at day .... } \\
\cline { 2 - 5 } & 4 & 5 & 6 & 7 \\
\hline I & 1 & 3 & 3 & 8 \\
\hline II & 0 & 1 & 2 & 7 \\
\hline III & 1 & 2 & 5 & 7 \\
\hline IV & 0 & 2 & 4 & 6 \\
\hline V & 1 & 3 & 5 & 8 \\
\hline VI & 2 & 5 & 6 & 9 \\
\hline
\end{tabular}

From the table above it can be seen that the highest number of deaths occurred on the seventh-day average larvae infected and die reached $75 \%$. This data will be compared with the treatment of Beauveria bassiana in the field.

\section{Applications of B.bassiana in the fields of research}

Applications Beauveria bassiana conidia done by mixing with water. Application spraying is done in the afternoon with the intensity 3 times in one week. Observations were made each week cover the range of the pest population, the diversity of types of pests, damage leaves and pest infestation levels in both fields of research. Observations in the first week, second and third after the second application of Beauveria bassiana on land not seen a significant difference. The types of pests of vegetables such as cauliflower $B$. oleracea snails, grasshoppers leaf, ladybugs, Plutella and Crossidolomia. In qualitative damage to the leaves of plants by insects or slightly higher in the control plants, the damage is massive because the pests only attack leaves lateral. Group grasshopper populations are low and do not cause severe damage was Plutella xylostella the solitary life also does not cause severe damage to both research fields. The leaves of the cabbage flowers on the lateral are perforated, not sporadic pest attack and not to attack the growing point (crop) cabbage plants harvested so that interest will continue to grow well. Observations on the third week, on land that is applied with Beauveria bassiana, the pest population remains relatively low, while on land without any treatment or control Crocidolomia binotalis populations have started to emerge. Population growth of Crocidolomia binotalis is quite rapid and sporadic, larvae are green with light green stripes back and on the left and right sides with the older color yellow on the the abdomen. After hatching, the larvae feed on leaves immediately with very voracious, especially the leaves inside covered by the outer leaves for larvae afraid of sunlight. The larvae live in groups, if attacks increase, the larvae will reach the point of growing crops or crop cauliflower. As a result of this attack, cabbage plants failed to form interest and result in loss of harvest (yield loss). Of the 75 
Sularno, Edi Azwar : Development of Biopesticide Bauveria bassiana Bals. (Vuill) Fungi For Pest Control Vegetable in Berastagi.

plants on land control, attack the crop reaches comparatively quite high, reaching at week 3 contained 5 plants damaged or approximately $6.7 \%$ in the five weeks to 9 plants, or about $12 \%$, and at week 7 reaches 13 plants or 17.3\%. In field applied while Beauveria bassiana, Crocidolomia binotalis attacks are relatively smaller. At three weeks there have been no plants are attacked, at week five there are three affected plants to the growing point and at week 7 there are 6 plants or about $8 \%$ that was attacked.
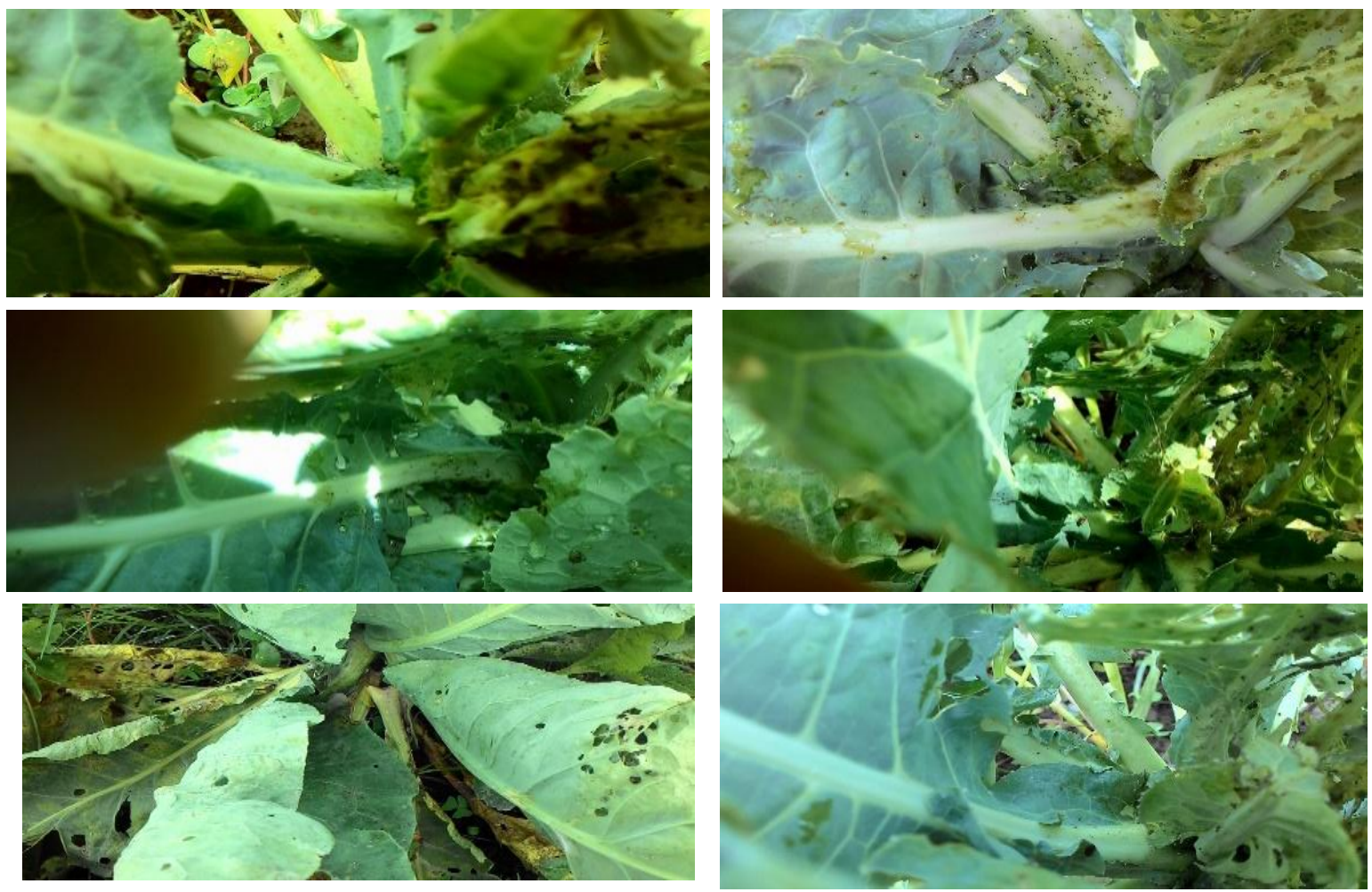

Figure 2. Damage to the leaves of the growing points or crop in cauliflower, cabbage crop failure flowering due to pests attacking at the growing point 
Sularno, Edi Azwar : Development of Biopesticide Bauveria bassiana Bals. (Vuill) Fungi For Pest Control Vegetable in Berastagi.

\section{REFERENCES}

Bale,J.S; J.C. Van Lenteren; and F. Bigler. 2008. Biological Control and sustainable food Production. Philos. Trans.R.Soc.Lond. B. Biol.Sci.

Blomquist G.J., and Vogt R.G., 2003, Biosynthesis, and detection of pheromones and plant volatiles - introduction and overview, In: Blomquist G.J., and Vogt R.G. (eds.), Insect Pheromone Biochemistry and Molecular Biology, Elsevier Academic Press, London, pp.137-200

Damalas, Christos A and Ilias G. Eleftherohorinos 2011. Pesticide Exposure, Safety Issues, and Risk Assessment Indicators Int J Environ Res Public Health. 2011 May; 8(5): 1402-1419.

Khan, Sehroon et al. 2012. Entomopathogenic Fungi as Microbial Biocontrol Agen. Molecular Plant Breeding, 2012, Vol. 3, No. 7

Nguya K. Maniania · David M. Bugeme · Vitalis W. Wekesa · Italo Delalibera Jr. · Markus Knapp. 2008. Role of entomopathogenic fungi in the control of Tetranychus

evansi

and Tetranychus urticae(Acari: Tetranychidae), pests of horticultural crops

Pell, J.K and Shah, P.A. 2003. Entomopathogenic fungi as biological control agents. Appl Microbial Biotechnol (2003)

Roberts D.W., and St. Leger R.J., 2004, Metarhizium spp., cosmopolitan insect-pathogenic fungi: mycological aspects, Adv. Appl. Microbiol., 54: 1-70

Takhur, Rupesh, and Sandhu, ,Sardul S. 2009. Distribution, occurrence and natural intervertebrate host of indigenous entomopathogenic fungi of Central India. Indian J Microbiol (March 2010) 50(1) : 8996

Wraight S.P., and Carruthers R.I., 1999, Production, delivery, and use of mycoinsecticides for control of insect pests of field crops. In: Hall F.R., and Menn, J.J. (eds.), Biopesticides: Use and delivery, Humana Press, Totowa, New Jersey, pp.233-269 